\title{
Can HbAlc and One-Hour Glucose Concentration in Standard OGTT Be Used for Evaluation of Glucose Homeostasis in Childhood?
}

\author{
Gül Yeşiltepe Mutlu, Elif Özsu, Filiz Mine Çizmecioğlu, Şükrü Hatun \\ Kocaeli University Medical Faculty, Department of Pediatrics, Division of Pediatric Endocrinology and Diabetes, Kocaeli, Turkey
}

\begin{abstract}
Objective: To investigate whether glycosylated hemoglobin $(\mathrm{HbA1c})$ and 1-hour glucose level in oral glucose tolerance test (OGTT) are useful parameters for evaluation of glucose homeostasis in childhood.

Methods: The medical records of 106 obese/overweight children aged from 7 to 18 years who underwent $0 \mathrm{GT}$ were evaluated retrospectively. The subjects were divided into 2 groups according to their one-hour glucose concentration. Group 1 consisted of subjects whose one-hour glucose level was $<155 \mathrm{mg} /$ $\mathrm{dL}$, and Group 2 consisted of subjects whose one-hour glucose level was $\geq 155$ $\mathrm{mg} / \mathrm{dL}$. The fasting and 2-hour glucose concentrations of the groups were compared. The sensitivity and specificity levels were determined using the ROC curve to assess the predictive value of $\mathrm{HbA} 1 \mathrm{c}$ for impaired glucose tolerance (IGT).

Results: The mean 2-hour glucose concentration of the subjects in Group 2 was significantly higher than that of the subjects in Group 1 (137.8 \pm 35.5 $\mathrm{mg} / \mathrm{dL}$ versus $113.1 \pm 21.2 \mathrm{mg} / \mathrm{dL}, \mathrm{p}<0.05)$. If a $5.5 \%$ cut-off value for $\mathrm{HbA} 1 \mathrm{c}$ was accepted as predictor of IGT, the sensitivity was $63 \%$ and specificity was $70 \% .31 \%$ of the subjects with HbA1c levels at or above $5.5 \%$ had IGT. This rate was significantly lower in subjects who had HbA1c levels below $5.5 \%(p<0.05)$

Conclusions: Obese/overweight children and adolescents whose 1-hour glucose level is $\geq 155 \mathrm{mg} / \mathrm{dL}$ in the standard OGT carry a high risk for IGT. Obese/overweight children and adolescents whose $\mathrm{HbA1c}$ level is at or above $5.5 \%$ may have IGT even though their fasting glucose level is normal, thus, $\mathrm{OGT}$ is necessary to evaluate the glucose tolerance.

Key words: HbA1c, one-hour glucose concentration, impaired glucose tolerance, childhood
\end{abstract}

Conflict of interest: None declared

Received: 28.11 .2012

Accepted: 22.01 .2013

\section{Introduction}

In recent years, obesity has become more common in childhood and parallel to this trend, an increase in the prevalence of type 2 diabetes in childhood and adolescence has also occurred, creating a need for new parameters to evaluate glucose homeostasis in children (1). One-hour glucose concentration of $\geq 155 \mathrm{mg} / \mathrm{dL}$ in oral glucose tolerance test (OGTT) is considered as a strong marker for the development of diabetes in adults (2,3). Abdul-Ghani et al (2) suggested that 1 -hour glucose concentration is more predictive of diabetes risk than the 2-hour glucose level in OGTT. Although the number of studies revealing this relationship in childhood is limited, Tfayli et al (4) showed the relationship between 1-hour glucose concentration and beta cell function regardless of glucose tolerance status in childhood.

Glycosylated hemoglobin ( $\mathrm{HbA} 1 \mathrm{c}$ ) alone or in combination with other metabolic/clinical parameters can be used as a screening method for detecting glucose intolerance in adults $(5,6,7)$.

Studies in children and adolescents suggesting that $\mathrm{HbA} 1 \mathrm{c}$ is more predictive of glucose intolerance than 2-hour glucose concentration in OGTT are limited (8,9). In this study, we therefore aimed to investigate whether $\mathrm{HbA} 1 \mathrm{c}$ and 1-hour glucose in OGT are useful parameters for evaluation of glucose homeostasis in children and adolescents.

Address for Correspondence

Şükrü Hatun MD, Kocaeli University Medical Faculty, Department of Pediatrics, Division of Pediatric Endocrinology and Diabetes, Kocaeli, Turkey Gsm: +90 5323468006 E-mail: sukruhatun@gmail.com

(c) Journal of Clinical Research in Pediatric Endocrinology, Published by Galenos Publishing. 


\section{Methods}

The medical records of 106 obese/overweight children aged from 7 to 18 years (13.4 \pm 2.6 , median: 13.5 years) who underwent OGTT between February 2010 and February 2011 were evaluated retrospectively. The subjects were divided into 2 groups according to their 1- hour glucose concentration. Children whose 1-hour glucose level was $<155 \mathrm{mg} / \mathrm{dL}$ were included in Group 1, and Group 2 consisted of subjects whose 1-hour glucose level was $\geq 155 \mathrm{mg} / \mathrm{dL}$. Body mass index (BMI), blood pressure, blood lipid profile, fasting glucose (FG), and 2-hour glucose concentrations of the groups were compared.

The subjects underwent a standard 2-hour OGTT, receiving an oral glucose load of $1.75 \mathrm{~g} / \mathrm{kg}$ (maximum $75 \mathrm{~g}$ ) after a 1012-hour overnight fast. Blood samples were obtained at 0 , $15,30,60,90$, and 120 min for determination of glucose and insulin levels. The lipid profiles (total cholesterol, triglyceride, $H D L$, LDL, VLDL cholesterol), liver transaminases (SGOT, SGPT) and $\mathrm{HbA} 1 \mathrm{c}$ levels were measured in the 0 min samples. $\mathrm{HbA} 1 \mathrm{c}$ levels were measured by high-performance liquid chromatography (HPLC). Biochemical values were measured by commercial enzymatic methods (Aeroset automated analyzer, Abbott Diagnostics, IL, USA).

BMI was calculated as weight $(\mathrm{kg}) /$ height $(\mathrm{m})^{2}$, evaluated according to BMI reference percentiles of Turkish children, and was expressed as standard deviation score (SDS) (10). Obesity was defined as a BMI at or above the 95th percentile value and overweight as a BMI between 85th and 95th percentiles. Waist circumference (WC) was measured at the minimum circumference between the iliac crest and the rib cage. WC measurements were evaluated according to WC percentiles of Turkish children (11).

Impaired FG (IFG) was defined as a FG concentration between 100-125 mg/dL and impaired glucose tolerance (IGT) as a 2-hour glucose concentration between 140-199 $\mathrm{mg} / \mathrm{dL}$. Diabetes was defined as either a FG at or above 126 $\mathrm{mg} / \mathrm{dL}$ or a 2-hour glucose concentration in OGTT at or above $200 \mathrm{mg} / \mathrm{dL}$, as per the criteria of the American Diabetes Association (ADA) (12).

Homeostasis model assessment of insulin resistance (HOMA-IR) was calculated with the formula [(FG (nmol/L) $x$ fasting insulin $(\mathrm{mlU} / \mathrm{mL}) / 22.5$ ]. A level above 3.16 was accepted as a marker of insulin resistance (13).

The pubertal status of the subjects was evaluated according to Tanner staging, and stage 1 was accepted as prepubertal, stage 2-4 as midpubertal, and stage 5 as pubertal, respectively.

\section{Statistical Analysis}

The sensitivity and specificity levels were determined using $\mathrm{ROC}$ curve to assess the predictive values of $\mathrm{HbA} 1 \mathrm{c}$ in subjects with IGT. We used Chi-square and t-tests for comparison of the groups, one-way ANOVA for the comparison of the means and Pearson method for correlation analysis, respectively.

\section{Results}

Mean BMI value of the subjects was 31.5 \pm 5.1 (20.7-46) $\mathrm{kg} / \mathrm{m}^{2}$. Mean BMI-SDS was 2.6 \pm 0.6 SDS and mean WC was $94.6 \mathrm{~cm}$. Forty-eight percent of the subjects were pubertal, $43 \%$ were midpubertal, and $9 \%$ were prepubertal.

Mean FG was $78.7 \pm 10 \mathrm{mg} / \mathrm{dL}$ (54-104 mg/dL), mean 2-hour glucose concentration was $119.6 \pm 27.8 \mathrm{mg} / \mathrm{dL}$ (50$238 \mathrm{mg} / \mathrm{dL})$, and mean $\mathrm{HbA} 1 \mathrm{c}$ level was $5.3 \pm 0.5 \%$ (4-7.5\%). Three subjects ( $3 \%$ ) had IFG, 18 subjects $(17 \%)$ had IGT, and 1 subject (1\%) had diabetes according to their 2-hour glucose concentrations. Only one of the 18 subjects who had an IFG had IGT. Mean 30-minute insulin concentration of the group was $102.3 \pm 83 \mathrm{uU} / \mathrm{mL}$. Their mean plasma triglyceride level was $118.2 \pm 62.7 \mathrm{mg} / \mathrm{dL}$, total cholesterol level $163.1 \pm 52.4$ $\mathrm{mg} / \mathrm{dL}, \mathrm{HDL}$ cholesterol $43.5 \pm 11.8 \mathrm{mg} / \mathrm{dL}$, LDL cholesterol level was $92.9 \pm 27.1 \mathrm{mg} / \mathrm{dL}$, and VLDL cholesterol level $22.9 \pm 13.8 \mathrm{mg} / \mathrm{dL}$ (Table 1).

There was a negative correlation between the 2-hour glucose and the 30-minute insulin concentrations $(p<0.01)$ and positive correlations between the 2-hour glucose concentration and the FG level and between the 1-hour glucose and the HbA1c levels (Table 2). However, the 2-hour glucose concentration was not correlated with age, pubertal stage, BMI, BMI-SDS, or WC $(p=0.7,0.6,0.8,0.9$ and 0.7, respectively).

\section{HbA1c as a Predictor of IGT}

If a $5.5 \%$ cut-off value for HbA1c was accepted to be a predictor of IGT, the sensitivity was $63 \%$ and specificity

Table 1. Demographic, clinical and laboratory values of the study group

\begin{tabular}{ll|} 
N & 106 \\
\hline Age (years) & $13.4 \pm 2.6(7-18)$ (median: 13.5) \\
Gender (female/male) & $71(67 \%) / 35(33 \%)$ \\
Pubertal status (prepubertal, & $10(9 \%) / 45(43 \%) / 51(48 \%)$ \\
midpubertal, pubertal) (n) & $31.5 \pm 5.1(20.7-46)$ (median: 31.8) \\
BMI (kg/m²) & $2.6 \pm 0.6$ (0.9-4.5) (median: 2.6) \\
BMI-SDS & $94.6 \pm 11.6(65-123)$ (median: 94) \\
Waist circumference (cm) & $5.3 \pm 0.7$ (4-7.5) \\
HbA1c (\%) & $3(3 \%)$ \\
Impaired fasting glucose [n (\%)] & $102.3 \pm 83(1.7-476)$ \\
30 minute insulin level (uU/mL) & $18(17 \%)$ \\
Impaired glucose tolerance (n,\%) & $118.2 \pm 62.7$ (41-337) \\
Triglyceride level (mg/dL) & $163.1 \pm 52.4$ (40-575) \\
Total cholesterol level (mg/dL) & $43.5 \pm 11.8$ (4-71) \\
HDL level (mg/dL) & $92.9 \pm 27.1$ (13.6-176) \\
LDL level (mg/dL) & $22.9 \pm 13.8$ (10-94) \\
VLDL level (mg/dL) & \\
\hline BMI: body mass index, SDS: standard deviation score, HbA1c: glycosylated \\
hemoglobin, mean $\pm S D(R a n g e)$ values are shown
\end{tabular}


was $70 \%$ (Figure 1). Although the cut-off values of 5.2 and $5.3 \%$ had higher sensitivity (78 and $72 \%$, respectively), they had lower specificity (37 and $49 \%$, respectively). $31 \%$ of the subjects who had HbA1c levels at or above $5.5 \%$ had IGT, however, this rate was significantly lower in the subjects who had $\mathrm{HbA} 1 \mathrm{c}$ levels below $5.5 \%(10 \%)(\mathrm{p}<0.05)$. Although only one $(5.5 \%)$ of the 18 subjects with IGT had IFG, 12 (66.6\%) of them had $\mathrm{HbA} 1 \mathrm{c}$ at or above $5.5 \%$.

One-Hour Glucose Concentration as a Predictor of IGT

When Group 1 (subjects whose 1-hour glucose concentration was below $155 \mathrm{mg} / \mathrm{dL}$ ) and Group 2 (subjects whose 1-hour glucose concentration was $\geq 155 \mathrm{mg} / \mathrm{dL}$ ) were compared in terms of $\mathrm{BMI}, \mathrm{WC}$, lipid profiles and $\mathrm{HbA} 1 \mathrm{c}$ levels, no significant difference was observed. However, the mean values of FG and 2-hour glucose concentrations were significantly higher in Group 2 (Table 3).

\section{Discussion}

As in adults, obesity is a predisposing factor for type 2 diabetes in childhood and adolescence. The progression from

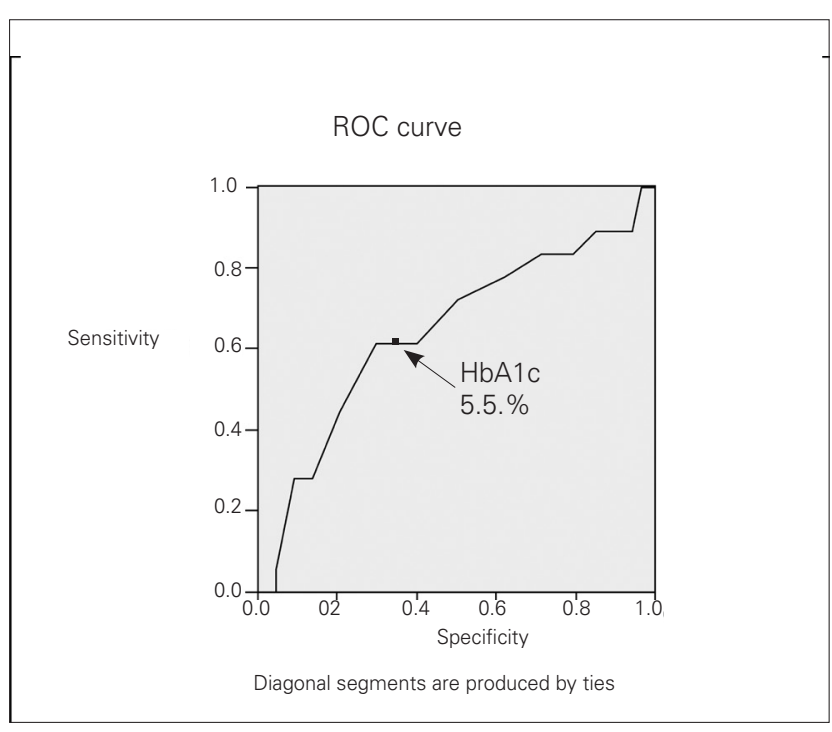

Figure 1. ROC curve normal glucose tolerance to type 2 diabetes mellitus involves an intermediate stage known as prediabetes or impaired glucose regulation, therefore the individuals who have IFG and/or IGT may be defined as prediabetic $(14,15)$. Although OGTT is the gold standard for diagnosis of glucose intolerance and diabetes, quest for a simpler and inexpensive screening test has become a current issue due to the difficulties in the implementation of OGTT to large populations (16).

A number of studies about the usage of $\mathrm{HbA} 1 \mathrm{c}$ alone or combined with clinical parameters as a screening test for diabetes in adulthood were published and different cut-off levels were suggested $(6,7,17,18,19)$. In a study conducted on 2298 high-risk adults, for instance, when a 5.6\% cut-off level for $\mathrm{HbA} 1 \mathrm{c}$ was used to detect IGT, the specificity and sensitivity $(51 \%, 66.2 \%$, respectively) were lower than the combination of a $\geq 5.6 \mathrm{mmol} / \mathrm{L}$ cut-off level for FG and a $\geq 5.6 \%$ cut-off level for $\mathrm{HbA} 1 \mathrm{c}$ (specificity was $82.4 \%$, sensitivity was $87.9 \%$ ) (6).

The number of studies suggesting $\mathrm{HbA} 1 \mathrm{c}$ as a predictive parameter for IGT in childhood is limited $(8,9,20)$. Tsay et al (9), who evaluated some parameters (FG, fasting insulin, triglyceride, cholesterol, blood pressure, BMI-Z score and $\mathrm{HbA} 1 \mathrm{c})$ as predictors of IGT, found that only $\mathrm{HbA} 1 \mathrm{c}$ is a significant predictor of IGT. They suggested a HbA1c cutoff level of $5.5 \%$ (sensitivity $85.7 \%$, specificity $56.9 \%$ ) and detected a significant increase in 2-hour glucose concentration correlated with this $\mathrm{HbA} 1 \mathrm{c}$ level (9). Shah et al (20) showed a moderate correlation between $\mathrm{HbA} 1 \mathrm{c}, \mathrm{FG}, \mathrm{HOMA}-\mathrm{IR}$ and 2-hour glucose concentration and reported that FG has the best correlation with 2-hour glucose concentration. In the same study, it was detected that a HbA1c cut-off level of $\geq 6 \%$ (specificity $96 \%$, sensitivity $99 \%$ ) is a good predictor of type 2 diabetes (19). In another adult study, the predictive value of FG in detecting IGT was shown to be more powerful compared to $\mathrm{HbA} 1 \mathrm{c}$. The predictive value of a cut-off level of $6.1 \mathrm{mmol} / \mathrm{L}$ for $F G$ alone was reported to be satisfactory, and the use of combination of $\mathrm{FG}$ and $\mathrm{HbA} 1 \mathrm{c}$ had no additional gain (21).

We found a significant correlation between 2-hour glucose levels and FG, HbA1c, and one-hour glucose levels. We suggest that the most appropriate cut-off level of $\mathrm{HbA} 1 \mathrm{c}$ for predicting IGT is 5.5\% (sensitivity 63\%, specificity $70 \%$ ).

\begin{tabular}{|c|c|c|c|c|c|}
\hline Parameter & Fasting glucose level & HOMA-IR & $\begin{array}{l}\text { 30-minute insulin } \\
\text { level in OGTT }\end{array}$ & $\begin{array}{l}\text { One-hour glucose level } \\
\text { in OGTT }\end{array}$ & HbA1c \\
\hline \multicolumn{6}{|c|}{ 2-hour glucose } \\
\hline $\mathrm{R}$ & 0.28 & 0.03 & -0.27 & 0.4 & 0.25 \\
\hline$P$ & $<0.01$ & 0.7 & $<0.01$ & $<0.01$ & $<0.01$ \\
\hline
\end{tabular}


Yeşiltepe Mutlu G et al.

The Predictors of Glucose Intolerance in Childhood

\begin{tabular}{|c|c|c|c|}
\hline & Group $1<155 \mathrm{mg} / \mathrm{dL}$ & Group $2 \geq 155 \mathrm{mg} / \mathrm{dL}$ & p \\
\hline $\mathrm{N}$ & 78 & 28 & \\
\hline Age (Years) & $13.3 \pm 2.6$ & $13.6 \pm 2.6$ & 0.5 \\
\hline Gender (F/M) & $52 / 26$ & $19 / 9$ & 0.9 \\
\hline Pubertal status & & & 0.1 \\
\hline Prepubertal & 6 & 4 & \\
\hline Midpubertal & 35 & 8 & \\
\hline Pubertal & 37 & 16 & \\
\hline BMI (kg/m²) & $31.4 \pm 5.1$ & $32 \pm 5.5$ & 0.6 \\
\hline BMI-SDS & $2.6 \pm 0.7$ & $2.72 \pm 0.6$ & 0.7 \\
\hline Waist circumference $(\mathrm{cm})$ & $94.8 \pm 12.2$ & $94.2 \pm 11.3$ & 0.8 \\
\hline Total cholesterol level & $161.2 \pm 58.8$ & $168.2 \pm 29.6$ & 0.5 \\
\hline HDL level & $44.4 \pm 11.5$ & $40.9 \pm 12.5$ & 0.2 \\
\hline LDL level & $91.6 \pm 25.2$ & $96.4 \pm 32.1$ & 0.4 \\
\hline Triglyceride level & $114.6 \pm 63.5$ & $128.1 \pm 60.3$ & 0.3 \\
\hline HbA1c (\%) & $5.2 \pm 0.4$ & $5.4 \pm 0.6$ & 0.3 \\
\hline Systolic blood pressure & $120.6 \pm 10.8$ & $122.2 \pm 16$ & 0.6 \\
\hline Diastolic blood pressure & $79.3 \pm 9$ & $80.3 \pm 11.1$ & 0.6 \\
\hline Fasting glucose concentration & $76.8 \pm 8.7$ & $84 \pm 11.5$ & $<0.05$ \\
\hline 1-hour glucose concentration & $118.7 \pm 17.4$ & $178.3 \pm 19$ & $<0.05$ \\
\hline 2-hour glucose concentration & $113.1 \pm 21.2$ & $137.8 \pm 35.5$ & $<0.05$ \\
\hline IGT (\%) & 8 & 42 & $<0.05$ \\
\hline
\end{tabular}

The frequency of IGT was 3 times higher among cases whose $\mathrm{HbA} 1 \mathrm{c}$ levels were $\geq 5.5 \%$ as compared to cases whose $\mathrm{HbA} 1 \mathrm{c}$ levels were $<5.5 \%$. IFG was detected in only $5.5 \%$ of the cases with IGT. However, HbA1c levels were at or above $5.5 \%$ in $66.6 \%$ of the cases with IGT. This relationship indicates that the obese/overweight children and adolescents with $\mathrm{HbA} 1 \mathrm{c}$ levels of $\geq 5.5$ are at high risk for IGT even though they do not have IFG.

We observed that 1-hour glucose concentration is correlated with 2-hour glucose concentration as well as with FG. Recent studies in adults have indicated the predictive value of 1-hour glucose concentration for the development of diabetes $(2,3)$. In the San Antonio Heart Study, 1611 adults underwent OGTT. At the end of a 7-8 year follow-up period, the risk of type 2 diabetes was $2.9 \%$ among the cases whose 1 -hour glucose concentration was $<155 \mathrm{mg} / \mathrm{dL}$, while the risk was higher (15.3\%) in the cases whose 1-hour glucose concentration was $>155 \mathrm{mg} / \mathrm{dL}(\mathrm{p}<0.0001)(2)$. In another large study (the Botnia study), OGTT results in 2442 adults have shown that 1 -hour glucose concentration was more powerful predictor for type 2 diabetes in comparison to 0-30-90-120-minute glucose concentrations (3).
Studies evaluating the predictive value of 1-hour glucose for development of type 2 diabetes in children and adolescent patients are scarce. Tfayli et al (4) found that obese/ overweight children whose 1-hour glucose was $\geq 155 \mathrm{mg} / \mathrm{dL}$ had significant low beta cell function. Similarly, in our study, IGT frequency was higher among the cases whose 1-hour glucose was at or above $155 \mathrm{mg} / \mathrm{dL}$. However, it is necessary to follow-up these cases for a longer period to evaluate the risk of type 2 diabetes.

In conclusion, the results of our study indicate that obese/ overweight children and adolescents whose 1-hour glucose level is at or above $155 \mathrm{mg} / \mathrm{dL}$ in the standard OGTT have a high risk for IGT and subsequent type 2 diabetes. The obese/ overweight children and adolescents whose $\mathrm{HbA} 1 \mathrm{c}$ level is at or above $5.5 \%$ may have IGT even though their FG is normal, thus OGTT is necessary to evaluate glucose tolerance.

\section{References}

1. Ogden $C L$, Carroll MD, Flegal KM. High body mass index for age among US children and adolescents, 2003-2006. JAMA 2008:299:2401-2405. 
2. Abdul-Ghani MA, Abdul-Ghani T, Ali N, Defronzo RA. Onehour plasma glucose concentration and the metabolic syndrome identify subjects at high risk for future type 2 diabetes. Diabetes Care 2008;31:1650-1655. Epub 2008 May 16

3. Abdul-Ghani MA, Lyssenko V, Tuomi T, DeFronzo RA, Groop $L$. Fasting versus postload plasma glucose concentration and the risk for future type 2 diabetes: results from the Botnia Study. Diabetes Care 2009;32:281-286. Epub 2008 Nov 18

4. Tfayli H, Lee SJ, Bacha F, Arslanian S. One-hour plasma glucose concentration during the OGTT: what does it tell about -cell function relative to insulin sensitivity in overweight/obese children? Pediatr Diabetes 2011;12:572579. Epub 2011 Apr 6

5. Saaristo T, Peltonen M, Lindström J, Saarikoski L, Sundvall J, Eriksson JG, Tuomilehto J. Cross-sectional evaluation of the Finnish Diabetes Risk Score: a tool to identify undetected type 2 diabetes, abnormal glucose tolerance and metabolic syndrome. Diab Vasc Dis Res 2005;2:67-72.

6. Hu Y, Liu W, Chen $Y$, Zhang M, Wang L, Zhou H, Wu P, Teng $X$, Dong $Y$, Zhou Jw, Xu H, Zheng J, Li S, Tao T, Hu Y, Jia $Y$. Combined use of fasting plasma glucose and glycated hemoglobin A1c in the screening of diabetes and impaired glucose tolerance. Acta Diabetol 2010;47:231-236. Epub 2009 Sep 17

7. Geberhiwot T, Haddon A, Labib M. HbA1c predicts the likelihood of having impaired glucose tolerance in highrisk patients with normal fasting plasma glucose. Ann Clin Biochem 2005;42:193-195.

8. Puri M, Freeman K, Garcia M, Nussbaum H, DimartinoNardi JR. Criteria for oral glucose tolerance testing of obese minority youth. J Pediatr Endocrinol Metab 2007;20:703-709.

9. Tsay J, Pomeranz C, Hassoun A, Zandieh SO, Rutledge J, Vogiatzi MG, Oberfield SE, Motaghedi R. Screening markers of impaired glucose tolerance in the obese pediatric population. Horm Res Paediatr 2010;73:102-107. Epub 2010 Feb 9

10. Bundak R, Furman A, Gunoz H, Darendeliler F, Bas F, Neyzi $\mathrm{O}$. Body mass index references for Turkish children. Acta Paediatr 2006;95:194-198.

11. Hatipoglu N, Ozturk A, Mazicioglu MM, Kurtoglu S, Seyhan S, Lokoglu F. Waist circumference percentiles for 7- to 17-year-old Turkish children and adolescents. Eur J Pediatr 2008;167:383-389. Epub 2007 May 9
12. American Diabetes Association. Standards of medical care in diabetes-2008. Diabetes Care 2008;31(Suppl 1):12-54.

13. Keskin M, Kurtoglu S, Kendirci M, Atabek ME, Yazici C. Homeostasis model assessment is more reliable than the fasting glucose/insulin ratio and quantitative insulin sensitivity check index for assessing insulin resistance among obese children and adolescents. Pediatrics 2005;115:500-503. Epub 2005 Mar 1

14. Tominaga $M$, Eguchi $H$, Manaka $H$, Igarashi $K$, Kato $T$, Sekikawa A. Impaired glucose tolerance is a risk factor for cardiovascular disease, but not impaired fasting glucose. The Funagata Diabetes Study. Diabetes Care 1999;22:920-924.

15. Cali AM, Caprio S. Prediabetes and type 2 diabetes in youth: an emerging epidemic disease? Curr Opin Endocrinol Diabetes Obes 2008;15:123-127.

16. Alberti KG, Zimmet PZ. Definition, diagnosis and classification of diabetes mellitus and its complications. Part 1: diagnosis and classification of diabetes mellitus provisional report of a WHO consultation. Diabet Med 1998;15:539-553.

17. Baral N, Koner BC, Karki P, Ramaprasad C, Lamsal M, Koirala S. Evaluation of new WHO diagnostic criteria for diabetes on the prevalence of abnormal glucose tolerance in a heterogeneous Nepali population-the implications of measuring glycated hemoglobin. Singapore Med J 2000;41:264-267.

18. Tabaei BP, Engelgau MM, Herman WH. A multivariate logistic regression equation to screen for dysglycaemia: development and validation. Diabet Med 2005;22:599-605.

19. Nelson KM, Boyko EJ; Third National Health and Nutrition Examination Survey. Predicting impaired glucose tolerance using common clinical information= data from the Third National Health and Nutrition Examination Survey. Diabetes Care 2003;26:2058-2062.

20. Shah S, Kublaoui BM, Oden JD, White PC. Screening for type 2 diabetes in obese youth. Pediatrics 2009;124:573-579. Epub 2009 Jul 20

21. Mannucci E, Ognibene A, Sposato I, Brogi M, Gallori G, Bardini G, Cremasco F, Messeri G, Rotella CM. Fasting plasma glucose and glycated haemoglobin in the screening of diabetes and impaired glucose tolerance. Acta Diabetol 2003;40:181-186. 